\title{
Effects of marginal iodine deficiency on thyroid hormone production, distribution and transport in nonpregnant and near-term pregnant rats
}

\author{
P M Versloot, J P Schröder-van der Elst, D van der Heide and L Boogerd \\ Department of Human and Animal Physiology, Agricultural University, Haarweg 10, 6709 PJ Wageningen, The Netherlands \\ (Correspondence should be addressed to D van der Heide)
}

\begin{abstract}
During pregnancy maternal thyroid hormones are of great importance for normal development of the central nervous system of the fetus. Iodine deficiency of the mother can result in an impaired development of the fetal brain. In large areas of the world iodine intake is moderately low. To study the effects of marginal iodine deficiency (MID) on the production, distribution, and transport of thyroxine $\left(\mathrm{T}_{4}\right)$ and 3,5,3'-tri-iodothyronine $\left(\mathrm{T}_{3}\right)$ in nonpregnant and near-term pregnant rats we performed kinetic experiments (three-compartment analysis). Despite unchanged plasma $\mathrm{T}_{4}$ and $\mathrm{T}_{3}$ during $\mathrm{MID}$, the production and plasma clearance rates of $\mathrm{T}_{4}$ decreased $30 \%(P=0.01)$ in MID nonpregnant (MID-C) rats. For $\mathrm{T}_{3}$, the plasma clearance rate was increased $70 \%(P=0.046)$, while the $\mathrm{T}_{3}$ production was more than doubled $(P=0.042)$ in MID-C rats. In MID near-term pregnant rats $\mathrm{T}_{3}$ production was decreased 20\% $(P=0.04)$. Hepatic deiodinase type I activity increased during MID in both nonpregnant and pregnant rats. It appears that during MID, rats are able to maintain their euthyroid status. The pronounced increase in transport of $\mathrm{T}_{4}$ from plasma to the fast pool observed in pregnant rats on a normal iodine diet did not occur during MID. In conclusion, in rats MID affects maternal thyroid hormone metabolism, thus influencing the availability of maternal $\mathrm{T}_{4}$ for the fetus.
\end{abstract}

European Journal of Endocrinology 138 713-718

\section{Introduction}

In large areas of the world iodine intake is insufficient. Severe iodine deficiency can result in miscarriage, stillbirth, and congenital abnormalities, as well as the more familiar goiter, cretinism, impaired brain function and hypothyroidism in children and adults (1).

In rats iodine deficiency can be induced by prolonged administration of a low iodine diet. This treatment results in a markedly increased weight of the thyroid and the 3,5,3'-tri-iodothyronine $\left(\mathrm{T}_{3}\right)$ to thyroxine $\left(\mathrm{T}_{4}\right)$ ratio in the thyroid, as well as the $\mathrm{T}_{3}$ to $\mathrm{T}_{4}$ ratio secreted by the thyroid $(2,3)$. In the iodine-deficient rat, plasma $\mathrm{T}_{4}$ is decreased and plasma thyrotropin (TSH) increased, while circulating $\mathrm{T}_{3}$ remains normal (4). In the rat normal pregnancy results in a decrease in both total and free $\mathrm{T}_{4}$ and $\mathrm{T}_{3}$ in the plasma $(5,6)$. This leads to reduced concentrations of $\mathrm{T}_{4}$ and $\mathrm{T}_{3}$ in the maternal tissues, except for $\mathrm{T}_{3}$ in the brain (5). The clearance of $\mathrm{T}_{4}$ from plasma is increased markedly, which can be a result of the transport of $\mathrm{T}_{4}$ to the fetal compartment (6).

Thyroid hormones are known to play an important role in brain maturation. Their absence during fetal development leads to irreversible brain damage. Studies of pregnant rats on a low iodine diet revealed that when iodine deficiency is severe enough to cause very low maternal plasma $\mathrm{T}_{4}$ levels, fetal plasma and tissues will suffer a shortage of $\mathrm{T}_{4}$ and $\mathrm{T}_{3}$ both before and after onset of fetal thyroid function $(7,8)$. During normal pregnancy mainly $\mathrm{T}_{4}$ is transported from mother to fetus (9).

In large populations of the world the iodine intake is only marginally deficient. Therefore, we induced an iodine deficiency in rats so marginal that growth and reproduction outcomes were not affected. The aim of this study was to determine the effects of marginal iodine deficiency (MID) on thyroid hormone metabolism in nonpregnant and near-term pregnant rats. $\mathrm{T}_{4}$ and $\mathrm{T}_{3}$ production, distribution, and transport in the plasma, the fast pool, and the slow pool were examined by performing a kinetic study using the three-compartment model developed by DiStefano et al. $(10,11)$. Liver and kidney are presumed to be the main components of the fast pool, whereas skin, muscle, and brain belong to the slow pool $(10,11)$.

Using this model we previously suggested that in near-term pregnant rats on a normal iodine diet, $\mathrm{T}_{4}$ is transported very rapidly from plasma to the fetoplacental compartment (6). In the present study we 
concentrated on the effects of MID on maternal thyroid hormone metabolism in rats, to answer the question, does MID affect the availability of thyroxine for the feto-placental compartment?

\section{Material and methods}

\section{Animals and diet}

Three-month-old female Wistar rats (CPB/WU, Iffa Credo, Brussels, Belgium) were used. The animals were individually housed at $22^{\circ} \mathrm{C}$, with alternating $14 \mathrm{~h}$ light and $10 \mathrm{~h}$ darkness periods. The rats were fed a semi-synthetic American Institute of Nutrition diet (12) with the addition of potassium iodide: $55 \mathrm{ng}$ (normal iodine diet; NID) or $2.9 \mathrm{ng}$ (MID) per gram of feed. The iodine-deficient groups were treated with $\mathrm{KClO}_{4}$ in their drinking water (13).

The rats were mated after at least two regular estrous cycles. The day that sperm appeared in the vaginal smear was taken as day 0 of gestation. The gestational period of the rat is 22 days.

\section{Design of the study}

MID treatment was started at least 2 weeks before mating for the pregnant groups and minimally 5 weeks before measurements for the nonpregnant groups. Surgery (insertion of the cannula) was conducted 1 week before measurements.

There were four groups of rats: (1) nonpregnant rats on a normal iodine diet, NID-C; (2) pregnant rats on a normal iodine diet, NID-P; (3) nonpregnant rats on MID, MID-C; (4) pregnant rats on MID, MID-P.

Daily feed intake and urinary iodide excretion were determined for all rats.

Kinetic experiments were performed on day 19 of gestation. After the kinetic experiment the animals were killed and maternal and fetal liver and brain were collected.

The experiments were approved by the University Committee on Animal Care and Use of the Agricultural University of Wageningen.

\section{Kinetic and analytical protocols}

The protocols of the kinetic experiments are already extensively described $(6,14,15)$. In short: $\left[{ }^{125} \mathrm{I}\right] \mathrm{T}_{4}$ and $\left[{ }^{131} \mathrm{I}\right] \mathrm{T}_{3}$ were administrated to the rats via a cannula in the right jugular vein (16). In the next $24 \mathrm{~h}$ blood samples were taken following the optimal time schedule according to DiStefano et al. $(10,11)$. The plasma samples were extracted and subjected to HPLC to separate the iodothyronines, according to the method described by Schröder-van der Elst \& van der Heide (17).

The endogenous concentrations of $\mathrm{T}_{4}$ and $\mathrm{T}_{3}$ in plasma were measured by means of a specific rat RIA
(18) on samples taken before the kinetic experiment was performed.

Plasma TSH was measured by the specific RIA developed for the rat by the National Institutes of Health (USA). Reference preparation RP-2 was used as a standard.

The method of calculation of the parameters of production, distribution and metabolism were as previously described $(6,14,15)$.

All data are expressed as means \pm S.E.M. Statistical analysis was performed by the Student's $t$-test using the Statistical Package for Social Sciences (SPSS) (19).

\section{Analytical determinations}

Urinary iodide was determined as described by Kolthoff \& Sandell (20).

Mitochondrial and cytosolic fractions from liver and brain were obtained by differential centrifugation, according to the separation scheme described by van Doorn et al. (21).

Liver and brain mitochondrial alpha-glycerophosphate dehydrogenase ( $\alpha$-GPD) was measured by means of the method described by Garrib \& McMurray (22).

Cytosolic malic enzyme (ME) was determined for liver and brain according to the method of Hsu \& Lardy (23).

The determination of type I deiodinase (ID-I) activity in liver homogenates was performed by the method described by Janssen et al. (24).

Protein was determined by the bicinchoninic acid method (Pierce Europe, Oud Beijerland, The Netherlands) using BSA as standard.

\section{Results}

\section{Urinary iodide excretion}

The effect of treatment with $1 \% \mathrm{KClO}_{4}$ for 2 days is demonstrated in Fig. 1A. Within a week after perchlorate treatment urinary iodide excretion had decreased to $0.4 \mu \mathrm{g} /$ day; it remained constant during the rest of the experimental period. Figure $1 \mathrm{~B}$ shows the daily urinary iodide excretion 4 weeks after the start of the diet. MID resulted in a sharp decrease in urinary iodide excretion. No effect of pregnancy on urinary iodide excretion was present in NID-P and MID-P rats.

\section{Body weight and plasma hormones}

Table 1 shows the body weight (BW) and plasma thyroid hormone and TSH levels. No significant effect of MID on maternal BW and the number of fetuses was found in MID-P rats. During pregnancy, in both the NID and MID groups, the plasma $\mathrm{T}_{4}$ and $\mathrm{T}_{3}$ decreased; plasma TSH did not change significantly. Plasma $\mathrm{T}_{4}$ and $\mathrm{T}_{3}$ values were unchanged in MID-C as well as in MID-P rats; plasma TSH was increased significantly in MID-C only. 
A

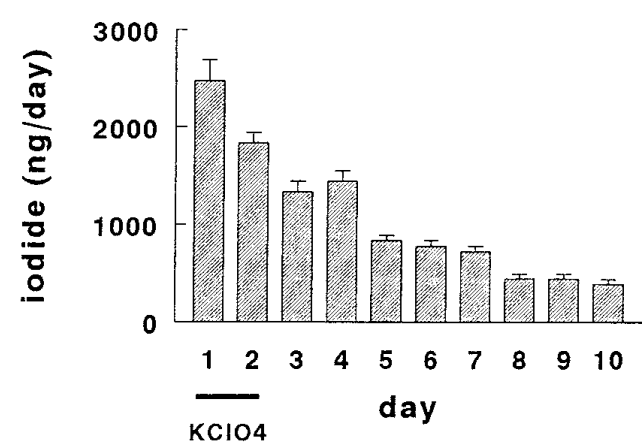

$\mathbf{B}$

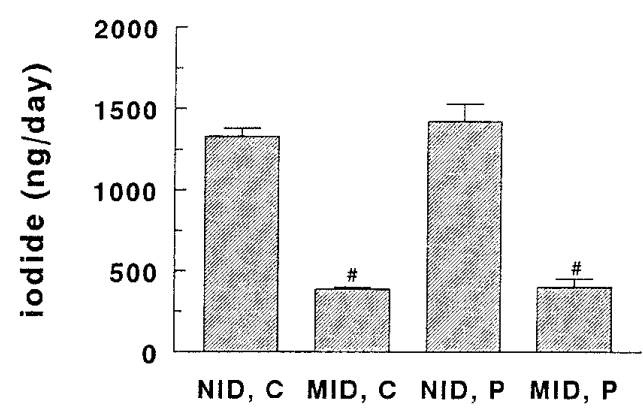

Figure 1 (A) The effect of $\mathrm{KClO}_{4}$ treatment on $24 \mathrm{~h}$ urinary iodide excretion. (B) Daily urinary iodide excretion in the four groups of rats. Values are means \pm S.E.M. ${ }^{\#} P<0.05$, MID vs NID. See Table 1 for $n$ values.

\section{$T_{4}$ kinetics}

The effect of pregnancy on the fractional turnover and transport rates of $\mathrm{T}_{4}$ was similar for NID-P and MID-P rats in comparison to their controls; $\mathrm{T}_{4}$ disappeared more quickly from all three pools in pregnant rats. No effects of MID on the kinetic parameters of $\mathrm{T}_{4}$ were found (data not shown).

The mean results of distribution volumes, pool sizes, and transport rates of $\mathrm{T}_{4}$ are summarized in Table 2 .

Effects of pregnancy In NID-P and MID-P rats the plasma clearance rate $(\mathrm{PCR})$ of $\mathrm{T}_{4}$ was increased; the production rate of $\mathrm{T}_{4}$ remained unchanged. The distribution volumes of $\mathrm{T}_{4}$ were not affected. The total amount of $\mathrm{T}_{4}$ decreased in the pregnant groups. This decrease was found in all three pools. The transport of
$\mathrm{T}_{4}$ changed only in NID-P rats. Transport to the fast pool and vice versa was more than doubled. This effect of pregnancy was not found in the MID group. The disposal of $\mathrm{T}_{4}$ decreased in both nonpregnant and pregnant rats.

Effects of MID MID resulted in a decrease in the plasma clearance rate and $\mathrm{T}_{4}$ production in MID-C rats only. The distribution volumes of $\mathrm{T}_{4}$ were not affected by MID. The pool sizes were decreased in MID-P rats; for MID-C rats no effect was found.

The transit times for the three pools and the total residence time for $\mathrm{T}_{4}$ are shown in Table 3. In NID-P and MID-P rats the transit times for $\mathrm{T}_{4}$ in plasma and the fast pool decreased. The total residence time also decreased. MID resulted in an increase in the total residence time for $\mathrm{T}_{4}$ in MID-C rats only.

\section{$T_{3}$ kinetics}

For $\mathrm{T}_{3}$ almost no significant alterations were found in the kinetic parameters. Only in MID-P rats was a decrease found in the transport rate from plasma to the fast pool, due to MID (data not shown).

Table 4 shows the distribution volumes, pool sizes, and transport rates of $\mathrm{T}_{3}$. The plasma clearance rate of $\mathrm{T}_{3}$ increased in the MID-C group only. Pregnancy resulted in a decrease in $\mathrm{T}_{3}$ production in MID-P rats. The effects of MID on the production of $\mathrm{T}_{3}$ were conflicting. In MID-C rats we found an increase, while in MID-P rats the $\mathrm{T}_{3}$ production decreased slightly.

The transport of $\mathrm{T}_{3}$ from plasma to the fast pool and vice versa decreased in MID-P rats only. The disposal of $\mathrm{T}_{3}$ increased in MID-C rats. In MID-P rats the disposal of $\mathrm{T}_{3}$ was even decreased.

In MID-P rats the increased transit time for $\mathrm{T}_{3}$ in plasma was the only change in transit times and total residence time found for $\mathrm{T}_{3}$ (Table 5).

\section{Enzymes}

Table 6 shows the activities of $\alpha$-GPD, ME, and ID-I in liver and brain. The $\alpha$-GPD activity in both maternal liver and brain decreased in the pregnant groups NID-P and MID-P; MID had no effect.

Table 1 Body weight and plasma thyroid hormone concentrations. Values are means \pm S.E.M.

\begin{tabular}{lcccc}
\hline & $\begin{array}{c}\text { NID-C } \\
(n=6)\end{array}$ & $\begin{array}{c}\text { MID-C } \\
(n=9)\end{array}$ & $\begin{array}{c}\text { NID-P } \\
(n=8)\end{array}$ & $\begin{array}{c}\text { MID-P } \\
(n=6)\end{array}$ \\
\hline Body weight $(\mathrm{g})$ & $211 \pm 6$ & $229 \pm 6$ & $304 \pm 6^{*}$ & $323 \pm 9^{*}$ \\
No. of fetuses & & & $11 \pm 1$ & $11 \pm 1$ \\
$\mathrm{~T}_{4}(\mathrm{nmol} / \mathrm{l})$ & $33.8 \pm 2.2$ & $34.6 \pm 3.0$ & $22.5 \pm 1.5^{*}$ & $17.2 \pm 1.7^{*}$ \\
$\mathrm{~T}_{3}(\mathrm{nmol} / \mathrm{l})$ & $0.62 \pm 0.04$ & $0.73 \pm 0.06$ & $0.53 \pm 0.06$ & $0.44 \pm 0.04^{*}$ \\
TSH $(\mathrm{ng} / \mathrm{ml})$ & $0.28 \pm 0.08$ & $0.75 \pm 0.10^{\dagger}$ & $0.49 \pm 0.06$ & $0.65 \pm 0.09$ \\
\hline
\end{tabular}

${ }^{*} P<0.05$, MID-P vs MID-C and NID-P vs NID-C.

${ }^{\dagger} P<0.05$, MID-C vs NID-C. 
Table 2 Parameters of distribution, volumes, pool sizes, and rates of transport of $\mathrm{T}_{4}$ (expressed per $100 \mathrm{~g}$ BW). Values are means \pm S.E.M.

\begin{tabular}{lcccc}
\hline & $\begin{array}{c}\text { NID-C } \\
(n=6)\end{array}$ & $\begin{array}{c}\text { MID-C } \\
(n=9)\end{array}$ & $\begin{array}{c}\text { NID-P } \\
(n=8)\end{array}$ & $\begin{array}{c}\text { MID-P } \\
(n=6)\end{array}$ \\
\hline PCR (ml/h) & $1.38 \pm 0.06$ & $0.93 \pm 0.07^{\dagger}$ & $1.73 \pm 0.04^{*}$ & $1.79 \pm 0.17^{*}$ \\
PR (pmol/h) & $47.2 \pm 4.2$ & $31.9 \pm 3.4^{\dagger}$ & $38.6 \pm 2.5$ & $30.4 \pm 3.0$ \\
Vtotal (ml) & $17.9 \pm 0.6$ & $16.1 \pm 0.5$ & $18.1 \pm 0.8$ & $15.9 \pm 1.5$ \\
Vp (ml) & $4.9 \pm 0.1$ & $4.5 \pm 0.1$ & $4.9 \pm 0.1$ & $4.7 \pm 0.2$ \\
V2 (ml) & $4.3 \pm 0.3$ & $4.5 \pm 0.3$ & $4.0 \pm 0.3$ & $3.6 \pm 0.7$ \\
V3 (ml) & $8.7 \pm 0.6$ & $7.1 \pm 0.5$ & $9.2 \pm 0.5$ & $7.6 \pm 1.0$ \\
Qtotal (pmol) & $615 \pm 51$ & $546 \pm 34$ & $421 \pm 32^{*}$ & $274 \pm 35^{\star \dagger}$ \\
Qp (pmol) & $166 \pm 12$ & $156 \pm 11$ & $110 \pm 7^{*}$ & $82 \pm 8^{*}$ \\
Q2 (pmol) & $145 \pm 12$ & $152 \pm 12$ & $89 \pm 9^{*}$ & $65 \pm 17^{\star}$ \\
Q3 (pmol) & $303 \pm 33$ & $239 \pm 18$ & $207 \pm 17^{*}$ & $127 \pm 16^{\star}$ \\
TRpf (pmol/h) & $973 \pm 114$ & $1392 \pm 363$ & $2574 \pm 317^{*}$ & $1250 \pm 249^{\dagger}$ \\
TRfp (pmol/h) & $952 \pm 115$ & $1376 \pm 363$ & $2563 \pm 313^{*}$ & $1233 \pm 250^{\dagger}$ \\
DRfo (pmol/h) & $23.6 \pm 2.1$ & $16.0 \pm 1.7^{\dagger}$ & $19.8 \pm 1.3$ & $15.4 \pm 1.4$ \\
TRps (pmol/h) & $162 \pm 23$ & $108 \pm 20$ & $188 \pm 32$ & $124 \pm 44$ \\
TRsp (pmol/h) & $138 \pm 21$ & $92 \pm 18$ & $169 \pm 31$ & $109 \pm 45$ \\
DRso (pmol/h) & $23.6 \pm 2.1$ & $16.0 \pm 1.7^{\dagger}$ & $19.8 \pm 1.3$ & $15.4 \pm 1.4$ \\
\hline
\end{tabular}

PCR, plasma clearance rate; PR, production rate; $V$, plasma equivalent distribution volume; $Q$, pool quantity; TRpf, TRfp, TRps, and TRsp, rates of transport between plasma and the fast and slow pools respectively, in each direction; DRfo and DRso, disposal rate from fast and slow pool respectively; p, plasma; 2, fast pool; 3, slow pool.

${ }^{*} P<0.05$, MID-P vs MID-C and NID-P vs NID-C.

${ }^{\dagger} P<0.05$, MID-P vs NID-P and MID-C vs NID-C.

In the fetal liver and brain no differences in $\alpha$-GPD activity were found between the NID and MID rats.

For ME no effect of pregnancy or MID was found in the liver. In the brain, however, ME activity increased in both NID-P and MID-P rats.

Pregnancy and MID both increased ID-I activity in the liver; this increase was additive.

\section{Discussion}

The aim of this study was to determine whether MID will affect thyroid hormone production, distribution, and transport in nonpregnant as well as near-term pregnant rats.

In most experimental studies severe iodine deficiency was induced, while in our study the rats were only marginally iodine deficient. This condition is much more common in iodine-deficient areas.

In our laboratory, MID rats receiving the same treatment as described for this study showed an increase in thyroid weight (13). During severe iodine deficiency decreased reproductive competence has been reported (7). However, neither retarded growth nor a decreased number of fetuses was observed, so the iodine deficiency achieved must have been marginal.

During MID, plasma $T_{4}$ and $T_{3}$ values remained unchanged, but plasma TSH increased slightly. Even under these moderate conditions $\mathrm{T}_{4}$ and $\mathrm{T}_{3}$ production and their PCR had already changed. The kinetic experiment revealed a decreased production of $\mathrm{T}_{4}$ in MID-C rats. The unaltered plasma $\mathrm{T}_{4}$ might possibly be explained by the decreased PCR, resulting in an increased mean residence time for $\mathrm{T}_{4}$ in the body.

The production of $T_{3}$ increased, but plasma $T_{3}$ was not affected by MID. We attribute this to the increased PCR.

Janssen et al. (24) found no effect of iodine deficiency on hepatic ID-I activity, even though $\mathrm{T}_{4}$ in their animals was lower. In the brain an increase in ID-II was found in iodine-deficient rats (24). In our study MID induced an

Table 3 Transit times and total residence time for $T_{4}$. Values are means \pm S.E.M.

\begin{tabular}{lcccc}
\hline & $\begin{array}{c}\text { NID-C } \\
(n=6)\end{array}$ & $\begin{array}{c}\text { MID-C } \\
(n=9)\end{array}$ & $\begin{array}{c}\text { NID-P } \\
(n=8)\end{array}$ & $\begin{array}{c}\text { MID-P } \\
(n=6)\end{array}$ \\
\hline Transit time (min) & & & & \\
$\quad$ Plasma & $9.5 \pm 0.8$ & $9.1 \pm 1.5$ & $3.7 \pm 0.9^{*}$ & $4.5 \pm 1.1^{*}$ \\
$\quad$ Fast pool & $9.7 \pm 1.1$ & $10.1 \pm 1.8$ & $3.5 \pm 1.2^{*}$ & $4.2 \pm 1.5^{*}$ \\
$\quad$ Slow pool & $127 \pm 15$ & $166 \pm 24$ & $99 \pm 23$ & $154 \pm 90$ \\
Total residence time (min) & $789 \pm 30$ & $1079 \pm 73^{\dagger}$ & $616 \pm 20^{*}$ & $560 \pm 86^{*}$ \\
\hline
\end{tabular}

${ }^{*} P<0.05$, MID-P vs MID-C and NID-P vs NID-C.

${ }^{\dagger} P<0.05$, MID-C vs NID-C. 
Table 4 Parameters of distribution volumes, pool sizes, and transport rates of $T_{3}$ (expressed per $100 \mathrm{~g}$ BW). Values are means \pm S.E.M.

\begin{tabular}{|c|c|c|c|c|}
\hline & $\begin{array}{l}\text { NID-C } \\
(n=6)\end{array}$ & $\begin{array}{l}\text { MID-C } \\
(n=9)\end{array}$ & $\begin{array}{l}\text { NID-P } \\
(n=8)\end{array}$ & $\begin{array}{l}\text { MID-P } \\
(n=6)\end{array}$ \\
\hline $\operatorname{PCR}(\mathrm{ml} / \mathrm{h})$ & $21.7 \pm 2.1$ & $36.6 \pm 5.4^{\dagger}$ & $26.1 \pm 2.8$ & $24.9 \pm 2.4$ \\
\hline PAR (pmol/h) & $13.4 \pm 1.5$ & $27.6 \pm 5.0^{\dagger}$ & $13.3 \pm 1.1$ & $10.3 \pm 0.4^{\star \dagger}$ \\
\hline $\mathrm{PR}(\mathrm{pmol} / \mathrm{h})$ & $14.6 \pm 1.7$ & $32.2 \pm 6.5^{\dagger}$ & $14.6 \pm 1.2$ & $11.4 \pm 0.5^{\star \dagger}$ \\
\hline Vtotal (ml) & $209 \pm 20$ & $278 \pm 21^{\dagger}$ & $194 \pm 15$ & $224 \pm 39$ \\
\hline $\mathrm{Vp}(\mathrm{ml})$ & $4.8 \pm 0.1$ & $4.8 \pm 0.6$ & $4.9 \pm 0.1$ & $4.8 \pm 0.2$ \\
\hline V2 (ml) & $28.6 \pm 2.1$ & $35.1 \pm 5.1$ & $33.1 \pm 4.3$ & $24.9 \pm 3.4$ \\
\hline V3 (ml) & $176 \pm 19$ & $238 \pm 21$ & $180 \pm 27$ & $194 \pm 37$ \\
\hline Qtotal (pmol) & $128 \pm 11$ & $216 \pm 24^{\dagger}$ & $111 \pm 13$ & $95 \pm 18^{*}$ \\
\hline Qp (pmol) & $3.0 \pm 0.2$ & $3.4 \pm 0.3$ & $2.6 \pm 0.3$ & $2.1 \pm 0.2^{*}$ \\
\hline Q2 (pmol) & $17.5 \pm 1.0$ & $24.4 \pm 2.9$ & $17.2 \pm 2.5$ & $10.6 \pm 1.4^{\star \dagger}$ \\
\hline Q3 (pmol) & $108 \pm 11$ & $176 \pm 25^{\dagger}$ & $92 \pm 14$ & $83 \pm 17^{*}$ \\
\hline TRpf (pmol/h) & $214 \pm 15$ & $256 \pm 30$ & $229 \pm 34$ & $100 \pm 20^{* \dagger}$ \\
\hline TRfp (pmol/h) & $207 \pm 15$ & $242 \pm 28$ & $222 \pm 34$ & $95 \pm 20^{* \dagger}$ \\
\hline DRfo (pmol/h) & $6.7 \pm 0.8$ & $13.8 \pm 2.5^{\dagger}$ & $6.6 \pm 0.6$ & $5.1 \pm 0.2^{* \dagger}$ \\
\hline TRps (pmol/h) & $53 \pm 7$ & $81 \pm 13$ & $56 \pm 11$ & $44 \pm 4^{*}$ \\
\hline TRsp (pmol/h) & $55 \pm 7$ & $85 \pm 13$ & $58 \pm 11$ & $47 \pm 5^{*}$ \\
\hline DRso (pmol/h) & $8.0 \pm 0.9$ & $18.5 \pm 4.0^{\dagger}$ & $8.0 \pm 0.6$ & $6.3 \pm 0.3^{\star \dagger}$ \\
\hline
\end{tabular}

PAR, plasma appearance rate; other abbreviations as in Table 2.

${ }^{*} P<0.05$, MID-P vs MID-C.

${ }^{\dagger} P<0.05$, MID-P vs NID-P and MID-C vs NID-C.

Table 5 Transit times and total residence time for $T_{3}$. Values are means \pm S.E.M.

\begin{tabular}{lcccc}
\hline & $\begin{array}{c}\text { NID-C } \\
(n=6)\end{array}$ & $\begin{array}{c}\text { MID-C } \\
(n=9)\end{array}$ & $\begin{array}{c}\text { NID-P } \\
(n=8)\end{array}$ & $\begin{array}{c}\text { MID-P } \\
(n=6)\end{array}$ \\
\hline $\begin{array}{l}\text { Transit time (min) } \\
\text { Plasma }\end{array}$ & $0.67 \pm 0.01$ & $0.76 \pm 0.22$ & $0.57 \pm 0.04$ & $0.93 \pm 0.16^{*}$ \\
Fast pool & $4.99 \pm 0.36$ & $6.64 \pm 1.35$ & $4.78 \pm 0.66$ & $7.23 \pm 1.22$ \\
$\quad$ Slow pool & $114 \pm 15$ & $122 \pm 25$ & $95 \pm 10$ & $99 \pm 23$ \\
Total residence time (min) & $607 \pm 76$ & $544 \pm 95$ & $513 \pm 52$ & $553 \pm 94$ \\
\hline
\end{tabular}

${ }^{*} P<0.05$, MID-P vs NID-P.

increase in hepatic ID-I activity. Therefore, the increased $\mathrm{T}_{3}$ production might possibly be explained by enhanced $\mathrm{T}_{4}$ to $\mathrm{T}_{3}$ conversion in the liver.

We suggest that rats are able to maintain their euthyroid status during MID. The alterations in $\mathrm{T}_{4}$ and $\mathrm{T}_{3}$ production are compensated for by changes in the PCR, resulting in normal thyroid hormone values in plasma.
The alterations in thyroid hormone metabolism due to pregnancy are in agreement with previous findings for iodine-sufficient rats (6). There is a difference in the effects of MID on the production and metabolism of $\mathrm{T}_{4}$ during pregnancy and in the nonpregnant situation.

During pregnancy $\mathrm{T}_{4}$ production also decreased as a result of MID, but the PCR remained unchanged. This resulted in a decrease in the total amount of $\mathrm{T}_{4}$ in the

Table $6 \alpha$-GPD, ME, and ID-I in maternal and fetal liver and brain. Values are means \pm S.E.M.

\begin{tabular}{lcccc}
\hline & $\begin{array}{c}\text { NID-C } \\
(n=6)\end{array}$ & $\begin{array}{c}\text { MID-C } \\
(n=9)\end{array}$ & $\begin{array}{c}\text { NID-P } \\
(n=8)\end{array}$ & $\begin{array}{c}\text { MID-P } \\
(n=6)\end{array}$ \\
\hline$\alpha$-GDP in maternal liver & $257 \pm 19$ & $261 \pm 26$ & $186 \pm 10^{*}$ & $193 \pm 20^{*}$ \\
$\alpha$-GPD in maternal brain & $1558 \pm 110$ & $1538 \pm 76$ & $1174 \pm 63^{*}$ & $898 \pm 134^{*}$ \\
ME in maternal liver & $157 \pm 14$ & $147 \pm 13$ & $140 \pm 15$ & $116 \pm 7$ \\
ME in maternal brain & $101 \pm 3$ & $103 \pm 5$ & $165 \pm 22^{*}$ & $212 \pm 18^{*}$ \\
ID-I in maternal liver & $213 \pm 9$ & $266 \pm 14^{\dagger}$ & $281 \pm 12^{*}$ & $316 \pm 14^{*}$ \\
$\alpha$-GPD in fetal liver & & & $367 \pm 53$ & $448 \pm 76$ \\
$\alpha$-GPD in fetal brain & & & $20.2 \pm 2.1$ & $19.4 \pm 2.1$ \\
\hline
\end{tabular}

$\alpha$-GPD in milli optical density (mOD)/min/mg protein; ME in nmol NADP/min/mg protein; ID-I in $\mathrm{pmol} / \mathrm{min} / \mathrm{mg}$ protein ${ }^{*} P<0.05$, MID-P vs MID-C and NID-P vs NID-C.

${ }^{\dagger} P<0.05$, MID-P vs NID-P and MID-C vs NID-C. 
body. Striking is the effect of MID on the transport of $\mathrm{T}_{4}$ to the fast pool in pregnant rats. During normal pregnancy the transport of $\mathrm{T}_{4}$ to the fast pool and vice versa is markedly increased. We suggested previously that this is caused by the fetal compartment (6). However, in MID-P rats no increase in transport to the fast pool was found. This could indicate that during MID the transport of $\mathrm{T}_{4}$ to the fetal compartment is already diminished. This is exceedingly important, because it is mainly $\mathrm{T}_{4}$ that is transported from mother to fetus. The absence of maternal $\mathrm{T}_{4}$ during fetal development can cause damage to the central nervous system (9). However, we did not find any effect on $\alpha$-GPD activity in the fetal brain during MID. This might possibly be explained by an increase in fetal ID-II; during severe iodine deficiency the fetal brain is protected from hypothyroidism by an increase in the activity of ID-II (8).

The alterations in $\mathrm{T}_{3}$ metabolism due to MID found in pregnant rats are the exact opposite of the effects in nonpregnant rats. In MID-P rats the production and the PCR of $\mathrm{T}_{3}$ decreased slightly.

The transport of $\mathrm{T}_{3}$ from plasma to the fast pool and vice versa was decreased by 50\% in MID-P rats. This implies that, despite the markedly increased ID-I activity, locally produced $\mathrm{T}_{3}$ is decreased. This is possibly due to a decreased availability of the precursor, $\mathrm{T}_{4}$.

The present results demonstrate that in rats under these conditions marginal iodine intake influences maternal thyroid hormone metabolism. The total amount of $\mathrm{T}_{4}$ in the mother is decreased and less $\mathrm{T}_{4}$ is transported to the fetus. So, even MID seems to affect the availability of maternal $\mathrm{T}_{4}$ for the fetus.

\section{Acknowledgements}

We thank the PhD students A Luttikholt, M van Rij and $\mathrm{J}$ Verschoor for their contribution to the experiments and G P Bieger-Smith for correction of the text. Reagents used for the rat TSH assay were kindly provided by the Rat Pituitary Hormone Distribution Program of the National Institute of Diabetes, Digestive and Kidney Diseases, Bethesda, MD, USA.

\section{References}

1 Hetzel BS. Iodine deficiency disorders (IDD) and their eradication. Lancet 19832 1126-1129.

2 Greer MA, Grimm Y \& Studer H. Qualitative changes in the secretion of thyroid hormones induced by iodine deficiency. Endocrinology 196883 1193-1198.

3 Riesco G, Taurog A, Larsen PR \& Krulich L. Acute and chronic responses to iodine deficiency in rats. Endocrinology 1977100 303-313.

4 Santisteban P, Obregon MJ, Rodriguez-Pena A, Lamas L, Escobar del Rey F \& Morreale de Escobar G. Are iodine-deficient rats euthyroid? Endocrinology $19821101780-1789$.

5 Calvo R, Obregon MJ, Ruiz de Ona C, Ferreiro B, Escobar del Rey F \& Morreale de Escobar G. Thyroid hormone economy in pregnant rats near term: a 'physiological' animal model of nonthyroidal illness? Endocrinology 1990127 10-16.

6 Versloot PM, Gerritsen J, Boogerd L, Schröder-van der Elst JP \& van der Heide D. Thyroxine and 3,5,3'-triiodothyronine production, metabolism, and distribution in pregnant rats near term. American Journal of Physiology 1994267 860-867.

7 Escobar del Rey F, Pastor R, Mallol J \& Morreale de Escobar G. Effects of maternal iodine deficiency on the L-thyroxine and 3,5,3'-triiodo-L-thyronine contents of rat embryonic tissues before and after onset of fetal thyroid function. Endocrinology 1986118 1259-1265.

8 Obregon MJ, Ruiz de Ona C, Calvo R, Escobar del Rey F \& Morreale de Escobar G. Outer ring iodothyronine deiodinases and thyroid hormone economy: responses to iodine deficiency in the rat fetus and neonate. Endocrinology 1991129 2663-2673.

9 Calvo R, Obregon MJ, Escobar del Rey F \& Morreale de Escobar G. The rat placenta and the transfer of thyroid hormones from the mother to the fetus. Effects of maternal thyroid status. Endocrinology $1992131357-365$.

10 DiStefano III JJ, Jang M, Malone TK \& Broutman M. Comprehensive kinetics of triiodothyronine production, distribution, and metabolism in blood and tissue pools of the rat using optimized blood-sampling protocols. Endocrinology $1982110198-213$.

11 DiStefano III JJ, Malone TK \& Jang M. Comprehensive kinetics of thyroxine distribution and metabolism in blood and tissue pools of the rat from only six blood samples: dominance of large, slowly exchanging tissue pools. Endocrinology $1982111108-$ 117.

12 Ad Hoc Committee on Standards for Nutritional Studies. Report of the American Institute of Nutrition. Journal of Nutrition 19777 1340-1348.

13 Versloot PM, Schröder-van der Elst J, van der Heide D \& Boogerd L. Effects of marginal iodine deficiency during pregnancy: iodide uptake by the maternal and fetal thyroid. American Journal of Physiology 1997273 E1121-E1126.

14 Schröder-van der Elst JP, van der Heide D, DiStefano III JJ, van der Bent C, Kaptein E \& Visser TJ. Effects of 5,5-diphenylhydantoin on the metabolic pathway of thyroid hormone in rats. European Journal of Endocrinology 1997136 324-329.

15 Versloot PM, van der Heide D, Schröder-van der Elst JP \& Boogerd L. Maternal thyroxine and 3,5,3-triiodothyronine kinetics in near-term pregnant rats at two different levels of hypothyroidism. European Journal of Endocrinology 1998138 113-119.

16 Roelfsema F, van der Heide D \& Smeenk D. Circadian rhythms of urinary electrolyte excretion in freely moving rats. Life Sciences 198027 2303-2309.

17 Schröder-van der Elst JP \& van der Heide D. Effects of 5,5'diphenylhydantoin on thyroxine and 3,5,3'-triiodothyronine concentrations in several tissues of the rat. Endocrinology 1990 126 186-191.

18 Van der Heide D \& Visser-Ende $\mathrm{M} . \mathrm{T}_{4}, \mathrm{~T}_{3}$ and reverse $\mathrm{T}_{3}$ in the plasma of rats during the first 3 months of life. Acta Endocrinologica 198093 448-454.

19 SPSS Inc. SPSS/PC + STATISTICS 4.O. Chicago, IL: McGraw-Hill, 1990.

20 Kolthoff IM \& Sandell AB. Textbook of Quantitative Inorganic Analysis. New York: Macmillan Co., 1936.

21 van Doorn J, van der Heide D \& Roelfsema F. Sources and quantity of 3,5,3-triiodothyronine in several tissues of the rat. Journal of Clinical Investigation 198372 1778-1792.

22 Garrib A \& McMurray WC. A sensitive, continuous spectrophotometric method for assaying $\alpha$-glycerophosphate dehydrogenase: activation by menadione. Analytical Biochemistry 1984 139 319-321.

23 Hsu RY \& Lardy HA. Malic enzyme. Methods in Enzymology 1969 $13230-235$.

24 Janssen PLTMK, van der Heide D, Visser TJ, Kaptein E \& Beynen AC. Thyroid function and deiodinase activities in rats with marginal iodine deficiency. Biological Trace Element Research 1994 $40237-246$.

Received 6 October 1997

Accepted 16 February 1998 